\title{
Compulsive painting: a variant of hypergraphia?
}

\author{
A. Panico ${ }^{1}$, A. Parmegriani ${ }^{2}$ and M.R. Trimble ${ }^{3}$ \\ ${ }^{1}$ Neurological Service, PF Calvi Hospital, Noale, Italy, ${ }^{2}$ Etuto di Clinica Neurologica, \\ Dell'Universita'Di Bologna, Bologna, Italy and ${ }^{3} T$ The National Hospital for Neurology and \\ Neurosurgery, Queen Square, London WC1N 3BG, UK
}

Keywords: Hypergraphia - Epilepsy - Temporal lobe epilepsy

\section{INTRODUCTION}

Hypergraphia, the tendency towards extensive, and often compulsive writing, was described in temporal lobe epilepsy by Waxman and Geschwind (1974). They suggested that it was characteristic of the interictal syndrome, which also included in some cases such phenomena as aggressiveness, hyper-religiosity and changes of sexual behaviour.

The concept of hypergraphia in epilepsy has remained controversial, although some other case series have been described (Trimble, 1986). The writing tends to be repetitive, meticulous and often concerned with religious or moral issues. Furthermore, it may not be permanent, sometimes being driven by a cluster of seizures, or gradually waning with time.

In their original paper, Waxman and Geschwind (1974) noted some variants of hypergraphia. One of their patients dictated to a public stenographer, others wrote songs or poetry. In a second paper (Waxman and Geschwind, 1975) they noted a patient with extensive drawing. In this communication we describe two patients with temporal lobe epilepsy who had a period of the latter variant, compulsive and extensive drawing or painting.

\section{CASE HISTORIES}

\section{Case 1}

Patient K.H. was born in 1951, he was a premature extended breech delivery, and suffered postnatal oxygen damage, with retrolental fibroplasia. He has remained partially sighted since that time.

His first seizure occurred at the age of 8 , and at the age of 17 he was admitted to the Chalfont Centre for Epilepsy, Chalfont St Peter, UK, where he has remained a resident ever since.
On admission he was having around 20 complex partial seizures a month, which have continued with variable frequency in spite of many different anticonvulsant regimes.

His EEGs have revealed right temporal and bilateral occipital abnormalities, although MRI findings were normal.

He has always had limited cognitive abilities, with mental handicap, but has remained well motivated, and his level of social functioning has always been considered excellent.

Psychiatric problems first became noted at the age of 26, with a depressive illness, which was treated with antidepressants. Delusions appeared a year later, and by the age of 30 he developed a schizophrenia-like psychosis, with associated Schneiderian First Rank Symptoms. There were never any manic episodes.

The psychosis responded well to psychotropic medication, but since that time he has had periodic episodes of a paranoid illness, which have fluctuated in intensity.

At the age of 34 he went through a phase of producing a large number of drawings which, considering his visual limitations, were well formed. They were scenes of trees, which were repetitive within each drawing, and between drawings (see Fig. 1). There was a copious output over a limited period of time, following which his interest in drawing diminished, and he has not been productive for several years. This phase did not correspond to any mood fluctuations, or to any obvious fluctuation in his psychosis.

\section{Case 2}

R.E. was born in May 1944. He began to have seizures at the age of 46 . Clinically there were complex 


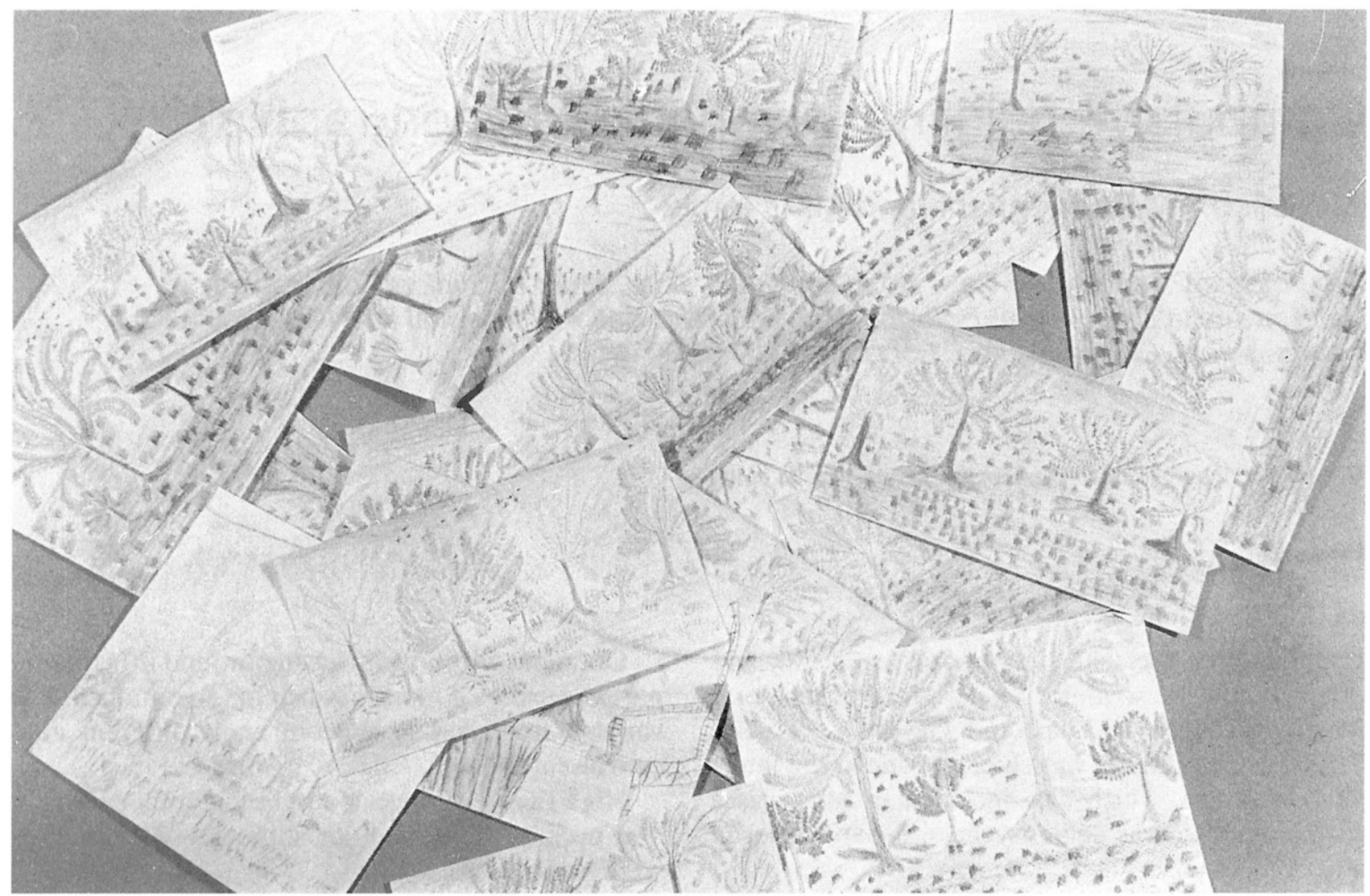

FIG. 1.

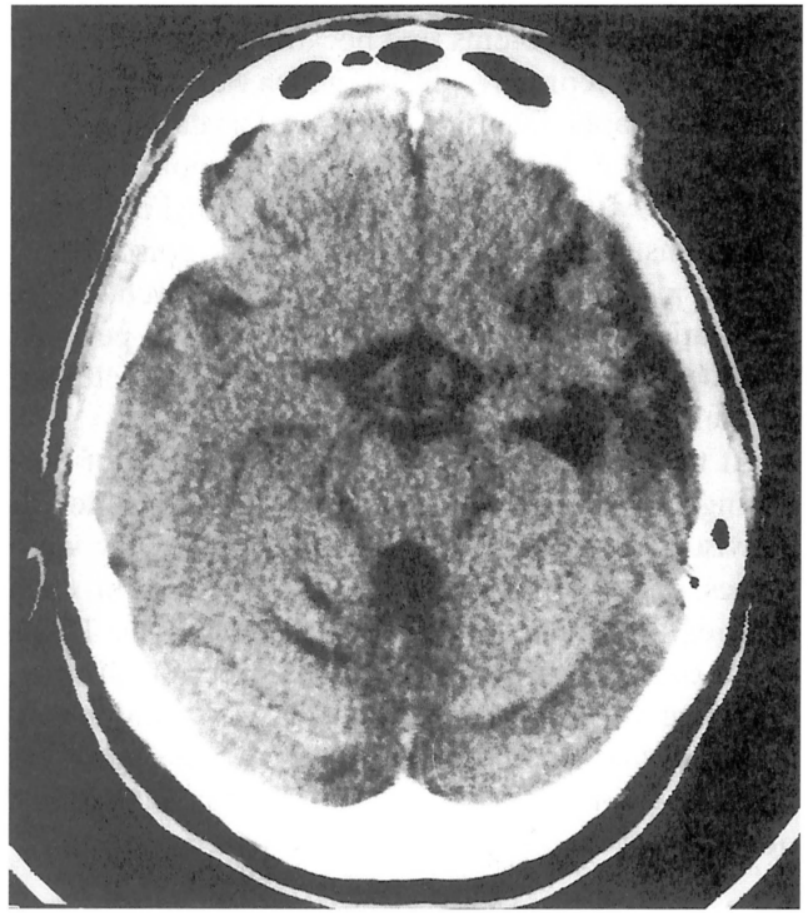

FIG. 2.

partial seizures, with an aura of smell, and an EEG showed left posterior temporal spikes. Cognitively he was normal. A CT scan revealed a left temporal tumour (see Fig. 2). This was operated on at age 48 and the pathology was an anaplastic astrocytoma.

It was at the age of 39 that he began to paint, initially landscapes, but from age 44 until his operation the theme became athletics (he had previously been a gym teacher, and a pole-vault and decathlon champion). Some repetition to the stylized figures are seen (see Fig. 3)

Following his operation, his seizures virtually abated, he has produced only two paintings, and they appear poorly organized and of considerably less quality than his previous art (see Fig. 4). Neuropsychological testing revealed some decline of verbal comprehension, compatible with his operation, but no generalized changes.

\section{DISCUSSION}

Although not common, hypergraphia has been reported often enough to be an accepted, if not controversial, neurological sign of CNS dysfunction. It is 
not only reported in temporal lobe epilepsy, although most descriptions and series are from patients with epilepsy (Trimble, 1986). Among possible variants, the tendency to excessive drawing and painting may occasionally be seen, and we have described two cases here. The celebrated artist Vincent Van Gogh probably also had this syndrome. When he died he left an extensive collection of letters to his family and other artists. In the last 2 years of his life he was painting a new oil painting every other day, in addition to watercolours (Trimble, 1991).

The mechanism of hypergraphia in epilepsy is unclear. The existing evidence suggests a link to temporal lobe epilepsy, and Waxman and Geschwind (1974) discussed it in terms of 'enhanced affective associations'. Robert et al. (1982) noted the associated elation, and Trimble (1986) discussed the role of diaschisis, release of activity in language areas occasioned by the lesion, which in reported cases was more often right-sided. In our patients there was no obvious link to alterations of affect, especially manic activity.

The variant of excessive pictorial representation may represent a different phenomenon from hypergraphia with the same underlying mechanism (i.e. diacheses with release of a behaviour). In our cases, one patient had a left-sided lesion, the other was bilateral. Alternatively it may represent part of the spectrum of the same clinical syndrome, namely the interictal syndrome of temporal lobe epilepsy, the manifestations of which vary from patient to patient depending upon other variables such as predisposition and previous writing and drawing abilities. However, both patients took to painting quite late in life, and patient 1 had quite limited skills.

The link rather specifically to the temporal lobe epilepsy is suggested further in our cases by the change of output following temporal lobectomy in patient 2. Although there were some cognitive changes in this patient following operation, they were the expected decline in verbal abilities, and would not have been expected to impinge on visually creative abilities directly.

In the same way that hypergraphia is under reported, and under recognised by many physicians managing epilepsy, the variant here reported, of excessive, compulsive drawing and painting may also be missed if not specifically inquired about. Further recognition of such behaviours in patients with neurological illness may allow a greater understanding of the mechanisms of creativity.

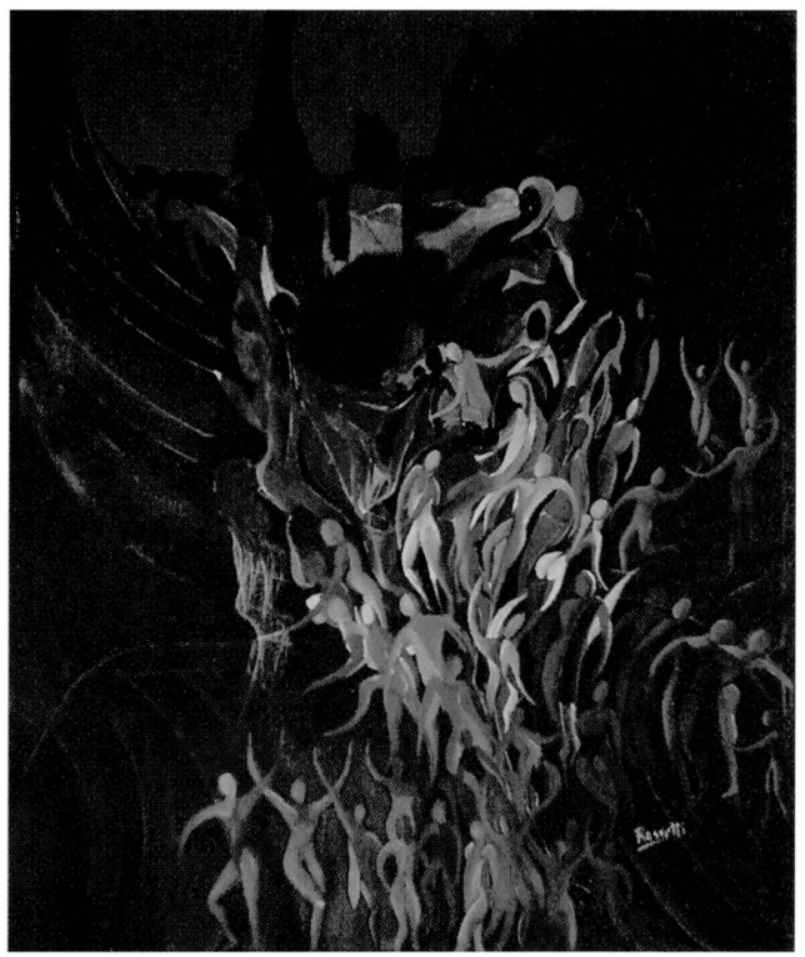

FIG. 3.

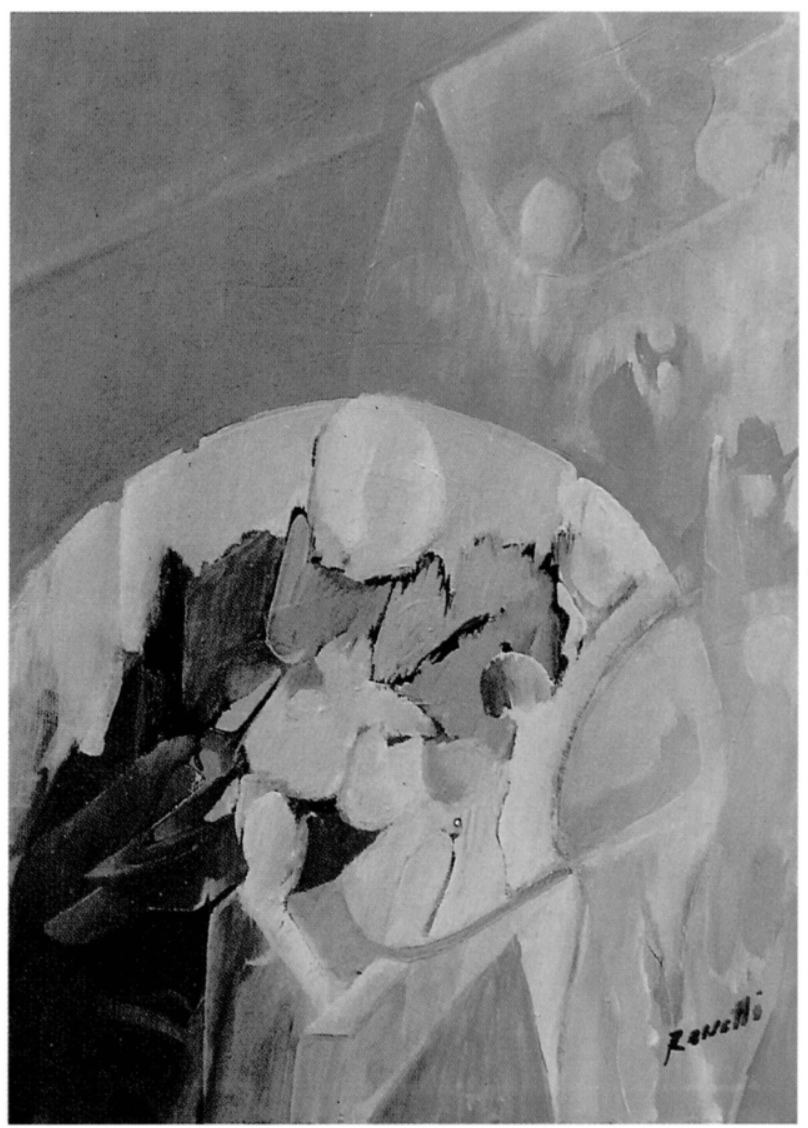

FIG. 4. 


\section{REFERENCES}

Roberts JKA, Robertson MM and Trimble MR (1982) The lateralising significance of hypergraphia in temporal lobe epilepsy. Journal of Neurology Neurosurgery and Psychiatry, 45, 131-138.

Trimble MR (1986) Hypergraphia. In: Aspects of Epilepsy and Psychiatry (Eds MR Trimble and TG Bolwig) pp. 75-88. J Wiley and Sons, Chichester.

Trimble MR (1991) The Psychoses of Epilepsy. Raven Press, New York.

Waxman SG and Geschwind N (1974) Hypergraphia in temporal lobe epilepsy. Neurology, 24, 629-636.

Waxman SG and Geschwind N (1975) The interictal behaviour syndrome of temporal lobe epilepsy. Archives of General Psychiatry, 32, 1580-1586. 


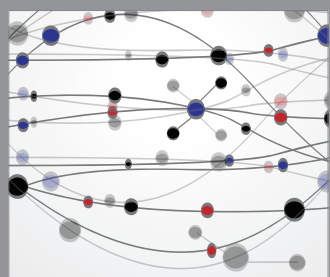

The Scientific World Journal
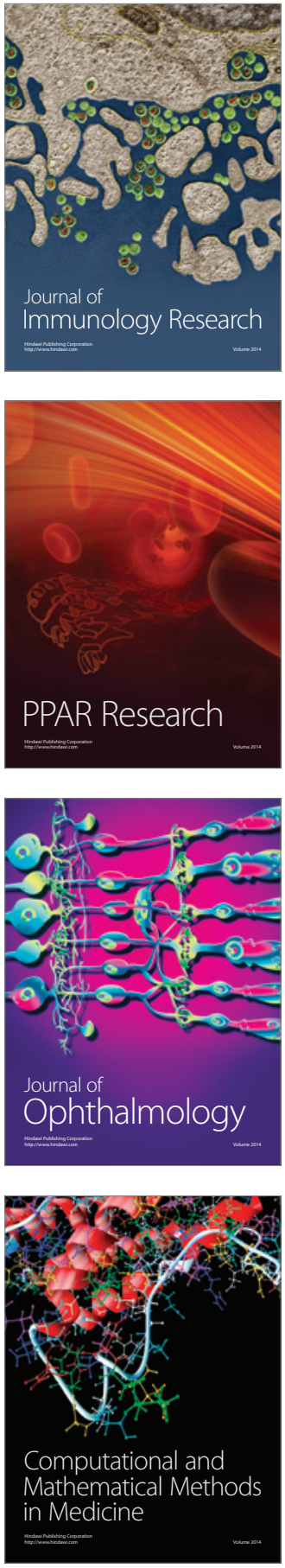

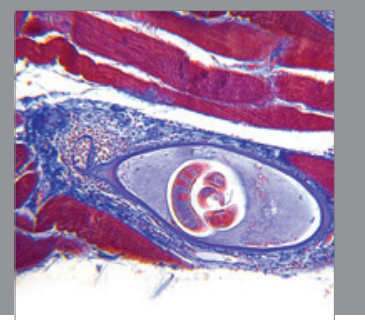

Gastroenterology

Research and Practice
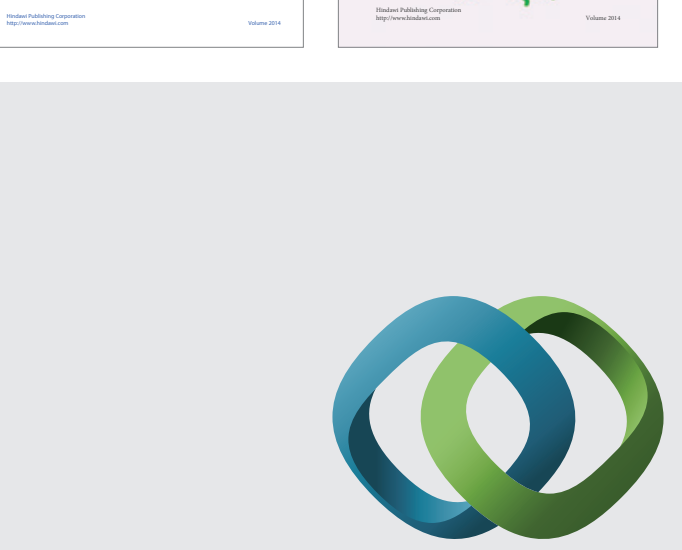

\section{Hindawi}

Submit your manuscripts at

http://www.hindawi.com
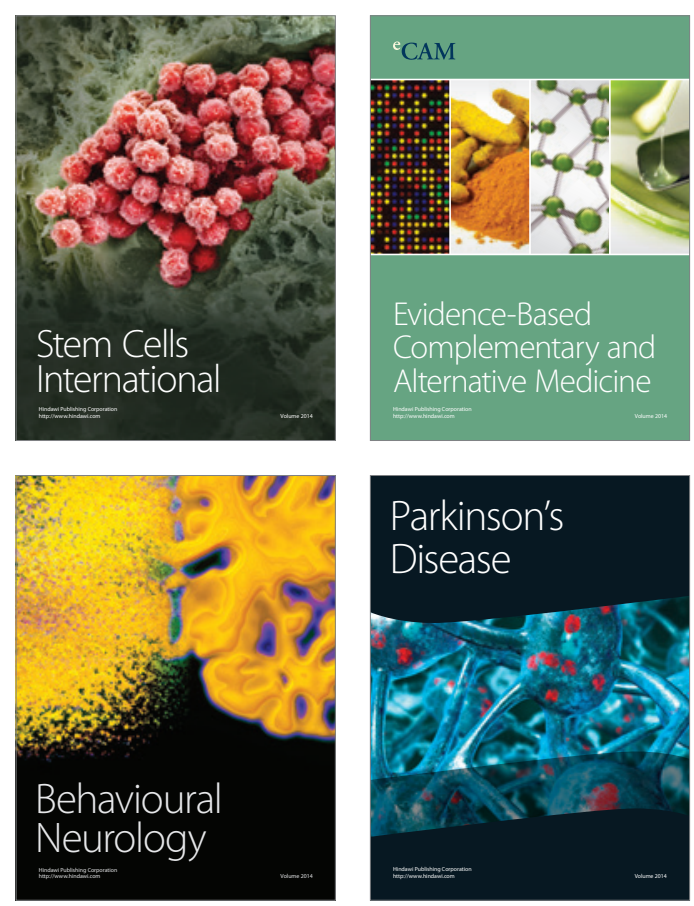

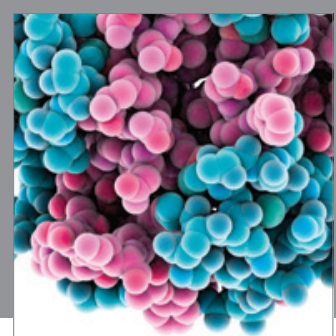

Journal of
Diabetes Research

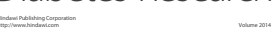

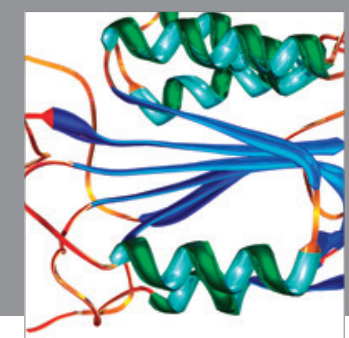

Disease Markers
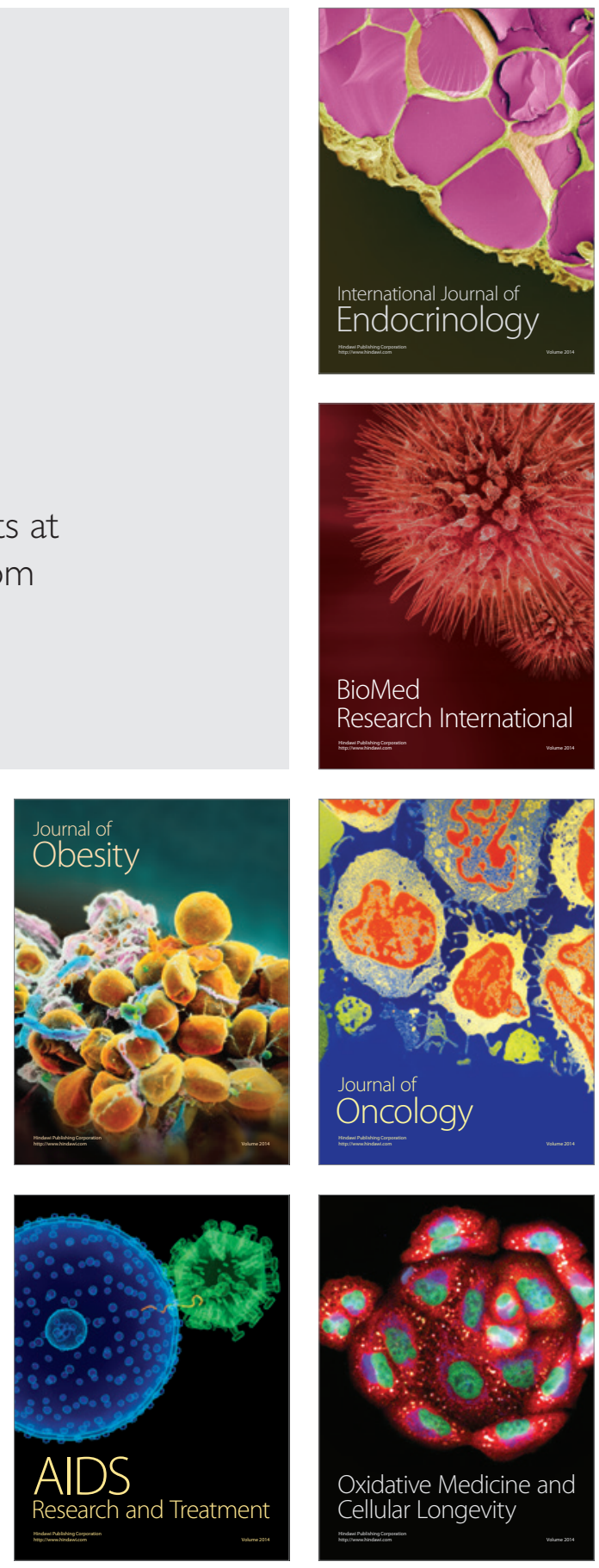